OPEN ACCESS

Edited by:

Wen Zhou,

Case Western Reserve University,

United States

Reviewed by:

Alessandro Antonelli,

University of Pisa, Italy

Pasqualino Malandrino,

University of Catania, Italy

*Correspondence:

Ana Luiza Maia

almaia@ufrgs.br

Specialty section

This article was submitted to

Cancer Endocrinology,

a section of the journal

Frontiers in Endocrinology

Received: 17 June 2019 Accepted: 02 October 2019 Published: 22 October 2019

Citation:

Nava CF, Scheffel RS, Cristo AP, Ferreira CV, Weber S, Zanella $A B$,

Paixão $F C$, Migliavaca $A$, Guimarães JR, Graudenz MS,

Dora JM and Maia AL (2019) Neoadjuvant Multikinase Inhibitor in Patients With Locally Advanced Unresectable Thyroid Carcinoma

Front. Endocrinol. 10:712

doi: 10.3389/fendo.2019.00712

\section{Neoadjuvant Multikinase Inhibitor in Patients With Locally Advanced Unresectable Thyroid Carcinoma}

\author{
Carla Fernanda Nava ${ }^{1}$, Rafael Selbach Scheffel ${ }^{1}$, Ana Patrícia Cristo ${ }^{2}$, Carla Vaz Ferreira ${ }^{1}$, \\ Shana Weber ${ }^{1}$, André Borsatto Zanella ${ }^{1}$, Francisco Costa Paixão ${ }^{3}$, Alceu Migliavaca ${ }^{3}$, \\ José Ricardo Guimarães ${ }^{3}$, Marcia Silveira Graudenz ${ }^{2}$, José Miguel Dora ${ }^{1}$ and \\ Ana Luiza Maia ${ }^{1 *}$ \\ ${ }^{1}$ Thyroid Unit, Endocrine Division, Faculdade de Medicina, Hospital de Clínicas de Porto Alegre, Universidade Federal do Rio \\ Grande do Sul, Porto Alegre, Brazil, ${ }^{2}$ Pathology Division, Faculdade de Medicina, Hospital de Clínicas de Porto Alegre, \\ Universidade Federal do Rio Grande do Sul, Porto Alegre, Brazil, ${ }^{3}$ Surgical Division, Faculdade de Medicina, Hospital de \\ Clínicas de Porto Alegre, Universidade Federal do Rio Grande do Sul, Porto Alegre, Brazil
}

Background: Papillary thyroid carcinoma (PTC) is the most common and less aggressive thyroid cancer, but some patients may display locally advanced disease. Therapeutic options are limited in these cases, particularly for those patients with unresectable tumors. Neoadjuvant therapy is not part of the recommended work up.

Methods: Report a case of an unresectable grossly locally invasive PTC successfully managed with neoadjuvant therapy and provide a systematic review (SR) using the terms "Neoadjuvant therapy" AND "Thyroid carcinoma."

Results: A 32-year-old man with a $7.8 \mathrm{~cm}$ (in the largest dimension) PTC was referred to total thyroidectomy, but tumor resection was not feasible due to extensive local invasion (trachea, esophagus, and adjacent structures). Sorafenib, a multikinase inhibitor (MKI), was initiated; a 70\% tumor reduction was observed after 6 months, allowing new surgical intervention and complete resection. Radioactive iodine (RAI) was administered as adjuvant therapy, and whole body scan (WBS) shows uptake on thyroid bed. One-year post-surgery the patient is asymptomatic with a status of disease defined as an incomplete biochemical response. The SR retrieved 123 studies on neoadjuvant therapy use in thyroid carcinoma; of them, 6 were extracted: 4 case reports and 2 observational studies. MKIs were used as neoadjuvant therapy in three clinical cases with $70-84 \%$ of tumor reduction allowing surgery.

Conclusion: Our findings, along with other reports, suggest that MKls is an effective neoadjuvant therapy and should be considered as a therapeutic strategy for unresectable grossly locally invasive thyroid carcinomas.

Keywords: thyroid carcinoma, multikinase inhibitors, neoadjuvant therapy, unresectable thyroid tumors, locally invasive thyroid tumors

\section{INTRODUCTION}

Thyroid carcinoma is the most common endocrine malignancy, accounting for $3.1 \%$ of the global incidence of cancers in 2018 (1). Differentiated thyroid carcinoma (DTC), including papillary (PTC) and follicular carcinoma (FTC), is derived from follicular cells of the thyroid gland and accounts for the majority of thyroid malignancies. Approximately 84\% of DTC tumors are PTC, 
affecting mainly female patients aged 40-59 years (2, 3). PTC is usually an indolent tumor, with an excellent prognosis. The initial therapeutic approach to DTC consists of total thyroidectomy, which might be followed by radioactive iodine (RAI) administration, and TSH suppression in selected cases (46). The incidence of unresectable PTC is unknown, and for these patients, therapeutic options are limited and disappointing.

Multikinase inhibitors (MKI) are drugs indicated for bulky or rapidly progressing iodine-refractory metastatic DTC, that result in symptomatic or threatening uncontrolled disease not amenable to other therapies (4). The antiproliferative MKI effect has been demonstrated in primary papillary dedifferentiated thyroid cancer (DePTC) cells whereas potent inhibition of angiogenesesis and growth were shown in nude mice bearing thyroid tumor xenografts $(7,8)$. The antitumor effects were confirmed in clinical studies, and currently, two MKI compounds have been approved by the Food and Drug Administration (FDA) for iodine-refractory PTC treatment: sorafenib and lenvatinib (9, 10). Sorafenib inhibits VEGFR-1, VEGFR-2 and VEGFR3, RET (including RET/PTC), RAF (including BRAF V600E), and platelet-derived growth factor B receptor. In the DECISION trial, the benefits of sorafenib were evidenced by higher rates of progression-free survival (PFS): 10.8 vs. 5.8 months, $P<$ 0.0001 . The best response in tumor reduction reached $60 \%$, but no benefit for overall survival was documented (9). Lenvatinib, the second MKI approved, inhibits VEGFRs 1,2, and 3, FGFRs 1,2,3, and 4; PDGFR $\alpha$, RET, and KIT signaling networks. The SELECT trial showed that patients with locally advanced disease in the lenvatinib group, even those that received another MKI before randomization, achieved a PFS benefit. The median PFS was 18.3 months in the lenvatinib group vs. 3.6 months in the placebo group (HR for progression or death, $0.21 ; 99 \%$ confidence interval, $0.14-0.31 ; P<0.001)$. Lenvatinib achieved the best response rate of $64.8 \%$ ( 4 complete responses) vs. $1.5 \%$ in the placebo group $(P<0.001)(10)$.

Neoadjuvant therapy refers to the administration of therapeutic agents before a primary treatment, usually surgery, aiming to reduce the size of the tumor (11). The use of MKI as neoadjuvant therapy is a well-established therapeutic tool for several human neoplasias (12-14). However, neoadjuvant treatment is an unusual event in the management of thyroid carcinoma. Indeed, it is not mentioned in the current DTC guidelines (4-6). Here, we report a patient presenting with locally advanced unresectable PTC who displayed a 70\% tumor reduction after neoadjuvant treatment with sorafenib, allowing complete surgical resection. Additionally, a systematic review of neoadjuvant therapies for thyroid carcinoma is provided.

\section{CASE REPORT}

\section{Clinical Presentation and Management}

A 32-year-old man presented with a cervical lesion of $7.8 \mathrm{~cm}$ (in the largest diameter), which was diagnosed as classical PTC by fine needle aspiration (FNA) cytology analysis and was referred to total thyroidectomy. However, the complete tumor resection was not feasible due to the invasion of trachea, esophagus and adjacent structures, the absence of a clear cleavage plane, along with compression, of cervical vessels, and only a partial resection of the left lobe of the thyroid was performed. The surgical product sent for histopathological examination showed a classical PTC with complex branching randomly oriented papillae with fibrovascular cores lined by cuboidal neoplastic cells. Carcinoma cell nuclei overlapped and showed finely dispersed optically clear chromatin (Figures 1A-D).

Immediate postoperative computed tomography (CT) displayed a lesion measuring $6.8 \times 3.4 \times 3.4 \mathrm{~cm}$ (Figure $2 \mathrm{~A}$ ) in contact with the carotid space, infiltrating the fat surrounding the vascular structures, with lateral deviation and reduction of the caliber of the internal jugular vein and no cleavage plan with the cervical musculature. Atypical lymph nodes on the left side of the neck up to $1.0 \times 1.0 \times 1.0 \mathrm{~cm}$ in diameter and three nodular lung opacities of $0.6,0.4$, and $0.4 \mathrm{~cm}$ diameters, considered non-specific, but suspicious for PTC metastasis were described.

Due to the advanced unresectable disease, neoadjuvant therapy with sorafenib ( $800 \mathrm{mg}$ per day) was started, aiming to reduce the lesion to allow surgical treatment. During sorafenib use, the patient presented hypertension, and grade II hand-foot syndrome both controlled with oral medications and topical measures. After 6 months of treatment, the large cervical lesion showed a reduction of $70 \%$ of the largest diameter from baseline $(2.0 \times 1.9 \times 1.6 \mathrm{~cm}$-Figure $2 \mathrm{~B})$ in $\mathrm{CT}$, defined as a partial response by RECIST criteria (15). Now, the lesion showed a cleavage plane with adjacent structures and cervical vessels. Sorafenib was stopped and surgery scheduled for 30 days later. A new CT immediately before surgery documented stable disease (target lesion size: $2.3 \times 2.2 \times 1.9 \mathrm{~cm}$ ).

The patient underwent a new surgical procedure, and the entire macroscopic PTC lesion was resected together with four cervical lymph nodes of the left jugular chain and mediastinal fat. Cervical vessels was preserved, but it was necessary to shave the trachea and esophagus and resect the left recurrent laryngeal nerve. The postoperative course was unremarkable, with no need for tracheostomy or ventilatory support, and the patient was discharged home on the third postoperative day. The histopathological analysis demonstrated a $2.5 \mathrm{~cm}$ classical PTC and another focus spanning $0.5 \mathrm{~cm}$ on the left lobe. Also, a $0.2 \mathrm{~cm}$ focus of PTC as identified in adipose tissue, 3 left jugular metastatic lymph nodes and positive surgical margins ( $\mathrm{pT} 4 \mathrm{a}$ $\mathrm{N} 1 \mathrm{~b} \mathrm{Mx}$-stage I). Compared to the pre neoadjuvant specimen, residual papillae were fibrotic and extensive areas of stromal fibrosis showing old hemorrhage and foreign body inflammation were observed (Figures 1E-H).

One month after surgery the patient received RAI therapy (100 mCi) administered in a stimulated TSH condition of endogenous hypothyroidism after withdrawing levothyroxine for 4 weeks (TSH $89.8 \mu \mathrm{UI} / \mathrm{mL}$; normal reference: 0.27$4.2 \mu \mathrm{UI} / \mathrm{mL}$ ). Serum thyroglobulin (Tg) showed a value of $42.6 \mathrm{ng} / \mathrm{mL}$ (sensibility $<0.1 \mathrm{ng} / \mathrm{mL}$ ) with positive antithyroglobulin antibody (AAT) $(6.4 \mathrm{UI} / \mathrm{mL}$; reference $<4.11$ $\mathrm{UI} / \mathrm{mL}$ ). A post-therapy whole body scan (WBS) was performed 10 days after the radioiodine administration, showing uptake at the thyroid bed. The disease status after 1 year of follow-up is an incomplete biochemical response (TSH: $9.1 \mu \mathrm{UI} / \mathrm{mL}$; Tg: $5.2 \mathrm{ng} / \mathrm{mL}$; AAT: $5.3 \mathrm{UI} / \mathrm{mL}$ and imaging exams without evidence of suspicious lesions). A written informed consent was obtained from the patient for the publication of this case report. 

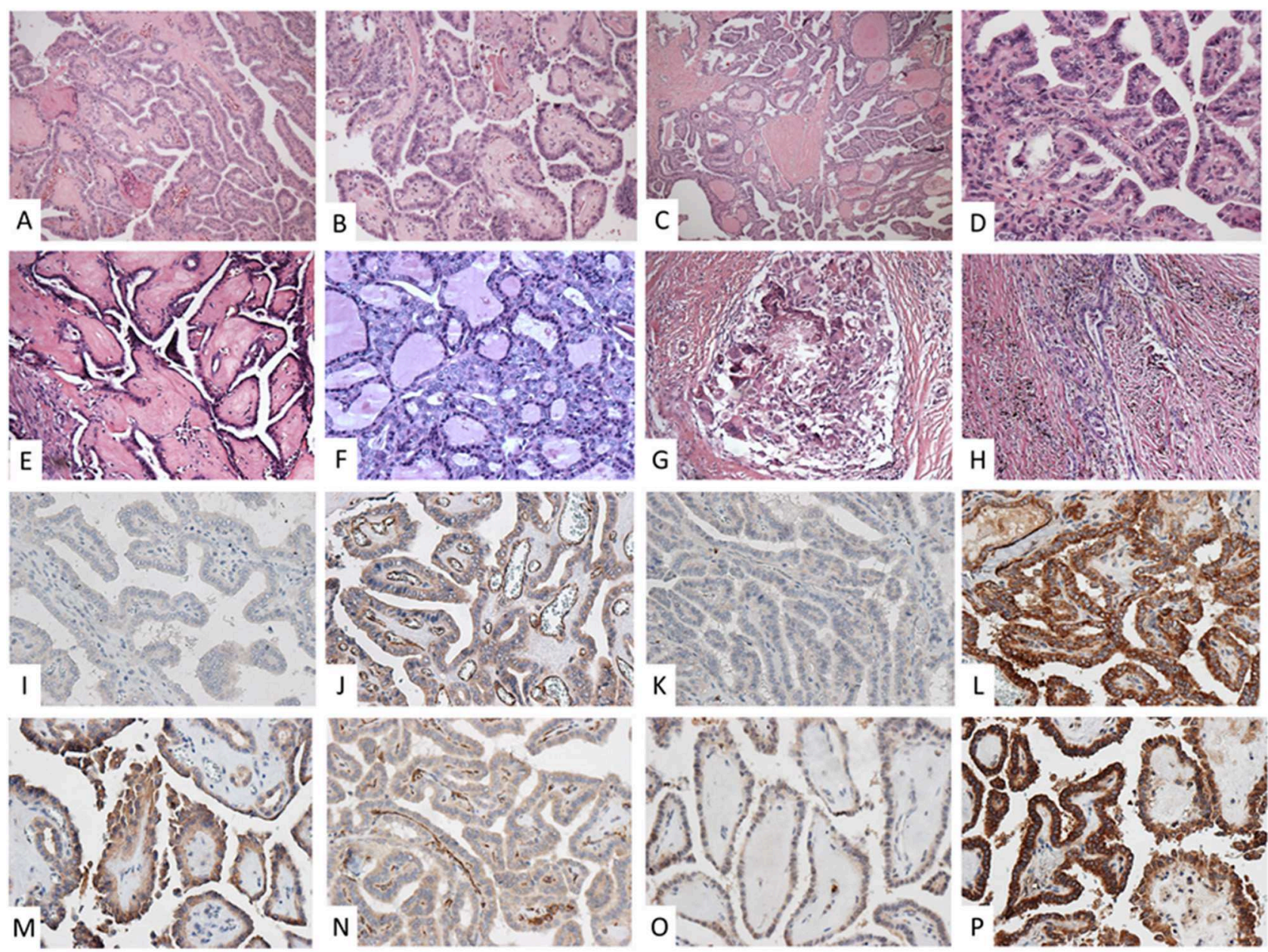

FIGURE 1 | Pre (A-D) and post-neoadjuvant (E-H) histopathological analysis of the classical papillary thyroid carcinoma surgical specimens. (A,B) Complex, branching, randomly oriented papillae with fibrovascular areas (HE 100X); (C,D) papillae lined by cuboidal cells, nuclei overlap with finely dispersed optically clear chromatin (HE 400X); (E) papillae showing fibrotic fibrovascular areas (HE 400X); (F) preserved neoplastic architecture (HE 400X); (G) foreign body granuloma (HE 100X); (H) densely fibrotic area showing old hemorrhage and residual infiltrative carcinoma (HE 100 X). Expression of VEGF, VEGFR-1, VEGFR2, and CD31 immunolabeling in pre (I-L) and post-neoadjuvant (M-P) surgical specimens, respectively. (I) light positivity in tumor cells and vascular endothelium; (J) highlighted a prominent vascular network in the neoplastic papillae; (K) negative staining; (L) intense staining in tumor cells maintained; (M,O) slightly increased positivity in tumor cells; (P) intense staining in tumor cells; (N) reduction in number and the caliber of vessels within fibrovascular areas (all 400X).

\section{Tumor Markers and Genetic Analysis}

Additionally to hematoxylin and eosin staining, immunohistochemistry analysis (IHC) was performed on thin sections $(3 \mu \mathrm{m})$ of previously formalin-fixed and paraffinembedded tissues. Expression of VEGF, VEGFR-1, VEGFR2, and CD31 immunolabeling was assessed in pre and post-neoadjuvant surgical specimens (Figures 1I-L). The immunoreactivity was scored as negative $(-)$ absence of labeling; $(+)$ discrete intensity; $(++)$ moderate intensity; and $(+++)$ accentuated intensity. Pre and post-treatment surgical specimens were compared, and the VEGF and VEGFR 1 displayed slightly increased positivity in tumor cells. On the other hand, a reduction in the number and caliber of vessels within fibrovascular cores when analyzing the CD31 antibody was observed (Figures 1M-P).

Molecular DNA analysis was performed in paraffin-embedded tumor tissue using the Magnesil Genomic Fixed Tissue System
(Promega, Madison, WI, USA), according to the manufacturer's instructions Point mutations at codon 600 of $B R A F$ and at codons 12,13 , and 61 of $\mathrm{K}-, \mathrm{H}-$, and $\mathrm{N}-\mathrm{R} A S$ were evaluated by PCR using specific primers and submitted to direct sequencing by standard procedures previously described (16). No known mutation was found in the analyzed exons and isoforms of the RAS gene. The BRAF V600E mutation was also negative.

\section{SYSTEMATIC REVIEW}

\section{Methods}

The electronic databases PubMed/Medline and Embase were searched for studies of neoadjuvant therapy for thyroid carcinoma. The reference lists of all identified articles were examined, and authors of included studies were consulted to obtain additional information when needed. 


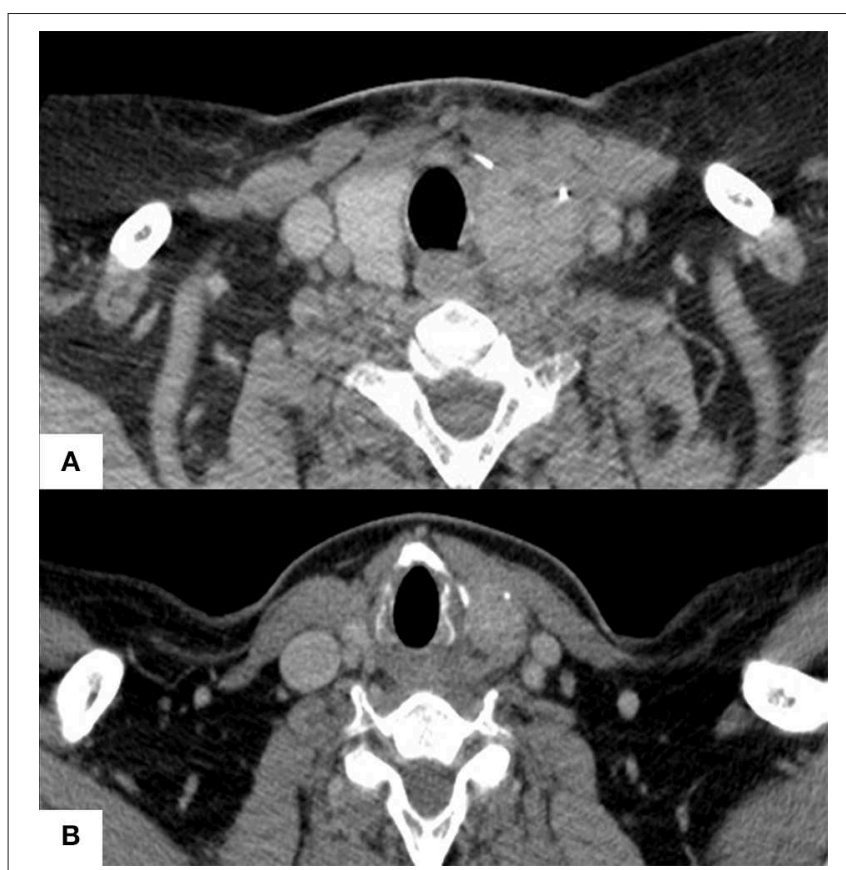

FIGURE 2 | Thyroid CT scans pre (A) and after 6 months (B) of neoadjuvant sorafenib therapy.

Two investigators (CFN and RSS), blinded to each other's rating, independently assessed study eligibility. All data were independently abstracted in duplicate using a standardized abstraction form. Differences in data extraction were resolved by a third party (JMD) and by referencing the original publication.

A search using the terms "Neoadjuvant therapy" AND "Thyroid carcinoma," with a language filter for articles in English on August 14th, 2018 retrieved 123 articles. Four manuscripts were excluded due to duplicated data. Based on title and abstract content, 88 studies were excluded because they did not include thyroid tumors, 15 because of lack of data from neoadjuvant therapy, 7 because they included thyroid tumors other than DTC or medullary thyroid carcinoma (MTC), 1 was not performed in humans, 1 was written in another language than English (French), and 1 review article. After the inclusion of the present case, a total of 5 case reports and 2 observational studies were included (Figure 3). A summarized description of the characteristics of the studies is shown in Table $\mathbf{1 .}$

This systematic review was planned and reported according to the Preferred Reporting Items for Systematic Reviews and Meta-Analyses (PRISMA) statement guidelines (17).

\section{RESULTS \\ Chemotherapy}

Two retrospective studies of neoadjuvant chemotherapy for patients with DTC considered inoperable were identified $(18,19)$. Treatment regimens consisted mostly of vinblastine, vinblastine plus adriamycin or other regimens in the two studies. Four follicular thyroid carcinomas (FTC) of 16 patients additionally received radiotherapy due to tumor progression despite chemotherapy and before surgery. Treatment response results were similar between PTC and FTC populations: 13/29 $(45 \%)$ and $7 / 16(44 \%)$ of patients with a tumor reduction of more than $50 \%$, respectively. All patients underwent surgery, allowing a total or near total thyroidectomy in $24 / 29(83 \%)$ and $11 / 16$ (69\%). After surgery, radioiodine was administered to $26 / 29$ (90\%) and 14/16 (87\%); and radiotherapy to $20 / 29(69 \%)$ and $12 / 16$ (75\%), respectively. In the follow-up 4/29 (14\%) and 2/16 (13\%) patients were disease-free; $2 / 29$ (7\%) and 4/16 (25\%) had persistent disease and 17/29 (59\%) and 8/16 (50\%) died from the disease, respectively. Mean disease-free survival was 110 months (7-201) for PTC and 110 months (5-218) for FTC patients.

\section{Radioiodine}

We identified one case report on the use of RAI as neoadjuvant therapy for PTC. A 57-year-old woman, with inoperable PTC, tumor size of $6.0 \mathrm{~cm}$ with symptoms of hoarseness and dyspnea. the patient received 3 doses of RAI from March 1995 to November 1996, with a cumulative radioiodine activity of 270 $\mathrm{mCi}$. At this time, the tumor diameter was $3.0 \mathrm{~cm}$, and total thyroidectomy was performed 30 days after the last RAI dosing; the patient was followed up for 1 year, but the final disease status was not reported (20).

\section{Multikinase Inhibitors}

Three previous case reports of neoadjuvant MKI for thyroid carcinoma were identified. The first report describes a 45year-old woman with suspected anaplastic thyroid carcinoma who initially received radiotherapy and chemotherapy (cisplatin and doxorubicin) for 5 weeks. As no response was observed, the chemotherapy was shifted to carboplatin and paclitaxel for 2 weeks, still in association with radiotherapy. Due to the absence of response, sunitinib $50 \mathrm{mg}$ daily was initiated in an intermittent schedule ( 4 weeks on and 2 weeks off medication). Total thyroidectomy was performed after 19 months of therapy when the tumor was considered potentially resectable. The histopathological analysis revealed MTC (21).

The second case was a 73-year-old man with a locally advanced PTC for whom surgery was considered highly invasive. He received lenvatinib $14 \mathrm{mg} /$ day for 18 weeks, resulting in a primary tumor reduction of $84 \%$, along with a $56 \%$ reduction of cervical lymph nodes metastases. Total thyroidectomy was then performed, preserving the patient's esophagus. The patient received radioiodine and did not present evidence of distant metastases at 10 months follow-up after surgery (22).

The third report was a 20 -year-old man with symptomatic PTC. Surgery was attempted but was stopped due to transoperative profuse tumor bleeding. At that time, sorafenib $800 \mathrm{mg}$ daily was started and maintained for 13 months. The tumor displayed a significant reduction, which allowed surgery. Due to the tracheal invasion, the patient underwent cervical external beam radiotherapy and radioiodine dosing (the total activity of $300 \mathrm{mCi}$ ). At 52 months of follow-up, the patient has stable, persistent structural disease (23). 


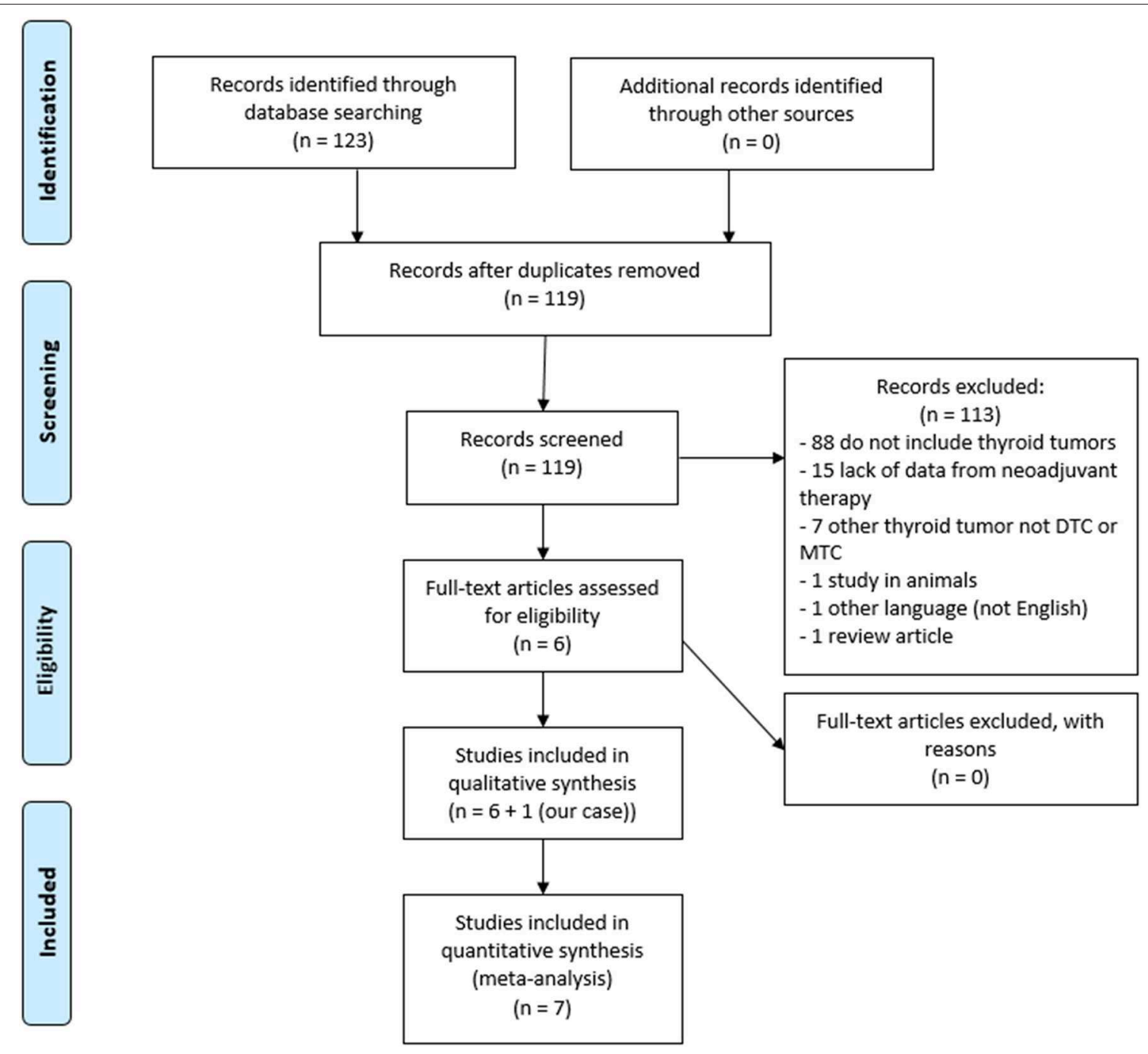

FIGURE 3 | Flow diagram of reference identification and selection.

\section{DISCUSSION}

PTC is usually an indolent tumor with an excellent prognosis. However, a small but significant percentage of patients with thyroid carcinomas may have locally advanced disease at initial presentation. Differentiated thyroid cancer (DTC) with Invasion of surrounding structures can lead to morbid procedures such as laryngectomy and tracheal resection. Invasion of trachea or larynx occur in 3.6$22.9 \%$ of thyroid cancer patients and advanced airway invasion with endoluminal tracheal involvement occurs in $0.5-1.5 \%$ of cases (24-26). Due to the disappointing results obtained with previous chemotherapy strategies, the current DTC guidelines do not recommend neoadjuvant therapy for patients with unresectable in whom surgery is contraindicated (4).

Indeed, a systematic literature search identified only two observational, retrospective studies of neoadjuvant chemotherapy for patients with inoperable thyroid carcinomas, both from the same Slovenian group $(18,19)$. Of note, $71 \%(n=32 / 45)$ of these patients required complementary RAI administration, and there is no report on the side effects. These findings limit the inferences about the risk/benefit balance of neoadjuvant chemotherapy for thyroid carcinoma. RAI administration was used as neoadvujant therapy in one case report, which limits conclusions.

MKI has only recently emerged as an alternative treatment for refractory-DTC thyroid cancer. However, it has rarely considered as a potential neoadjuvant therapy strategy for thyroid cancer. Here, we describe a case of a young male patient with unresectable grossly locally invasive PTC successfully managed with MKI neoadjuvant therapy. After MKI therapy, the patient underwent surgical resection and RAI administration and currently presents an incomplete biochemical status. A literature search 
TABLE 1 | Publications retrieved from the search in database on neoadjuvant therapy and thyroid carcinoma.

\begin{tabular}{|c|c|c|c|c|c|c|c|c|}
\hline Author & Country/Year & $\begin{array}{l}\text { Type of study/ } \\
\text { Tumor } \\
\text { histology }\end{array}$ & $\begin{array}{l}\text { Number } \\
\text { of } \\
\text { patients }\end{array}$ & $\begin{array}{l}\text { Age } \\
\text { (years or } \\
\text { mean } \\
\text { age) }\end{array}$ & Neoadjuvant therapy & Response to therapy & Surgery & Disease status \\
\hline Besic et al. & Slovenia/2012 & $\begin{array}{l}\text { Retrospective/ } \\
\text { Follicular or } \\
\text { Hurthle cell }\end{array}$ & 29 & 61 & $\begin{array}{l}\text { Vinblastine (19 patients); } \\
\text { vinblastine + adriamycin (5 } \\
\text { patients); or other ChT (5 } \\
\text { patients) }\end{array}$ & $\begin{array}{l}45 \% \text { patients with }>50 \% \\
\text { tumor reduction }\end{array}$ & $\begin{array}{l}15 \text { patients no residual tumor; } 10 \\
\text { patients microscopic residual } \\
\text { tumor; and } 4 \text { patients } \\
\text { macroscopic residual tumor }\end{array}$ & $\begin{array}{l}4 \text { excellent response } \\
2 \text { with persistent disease } \\
17 \text { deaths from the disease and } \\
6 \text { deaths from other causes }\end{array}$ \\
\hline Besic et al. & Slovenia/2013 & $\begin{array}{l}\text { Retrospective/PTC } \\
\text { and variants* }\end{array}$ & 16 & 63 & $\begin{array}{l}\text { Vinblastine (11 patients); } \\
\text { vinblastine + adriamycin ( } 2 \\
\text { patients); or other ChT ( } 3 \\
\text { patients). Of note, } 4 \text { patients } \\
\text { received neoadjuvant RhT due to } \\
\text { tumor progression }\end{array}$ & $\begin{array}{l}44 \% \text { patients with }>50 \% \\
\text { tumor reduction }\end{array}$ & $\begin{array}{l}2 \text { patients no residual tumor; } 10 \\
\text { patients microscopic residual } \\
\text { tumor; and } 4 \text { patients } \\
\text { macroscopic residual tumor }\end{array}$ & $\begin{array}{l}2 \text { excellent response } \\
4 \text { with persistent disease } \\
8 \text { deaths from the disease }\end{array}$ \\
\hline Shingu et al. & Japan/1998 & $\begin{array}{l}\text { Case } \\
\text { report/PTC }\end{array}$ & 1 & 57 & RAl $(180 \mathrm{mCl})$ & $50 \%$ of tumor reduction & $\begin{array}{l}\text { Total thyroidectomy, partial } \\
\text { resection of trachea, bilateral } \\
\text { modified neck dissection, and } \\
\text { upper mediastinal dissection }\end{array}$ & Alive for 1 year \\
\hline Cleary et al. & USA/2010 & $\begin{array}{l}\text { Case } \\
\text { report/MTC }\end{array}$ & 1 & 45 & $\begin{array}{l}\text { RhT + Cisplatin plus adriamycin } \\
\text { after carboplatin plus placlitaxel } \\
\text { and last sunitinib for } 19\end{array}$ & $\begin{array}{l}\text { Tumor reduction allowing } \\
\text { surgical resection }\end{array}$ & $\begin{array}{l}\text { Total thyroidectomy, resection of } \\
\text { the mediastinal mass, and a } \\
\text { central compartment and left } \\
\text { neck dissection }\end{array}$ & $\begin{array}{l}\text { Alive; calcitonin } 106 \mathrm{pg} / \mathrm{mL} \text {, } \\
\text { without evidence of macroscopic } \\
\text { disease }\end{array}$ \\
\hline \multicolumn{9}{|c|}{ Multikinase Inhibitors as Neoadjuvant Therapy } \\
\hline Tsuboi et al. & Japan/2017 & $\begin{array}{l}\text { Case } \\
\text { report/PTC }\end{array}$ & 1 & 73 & Lenvatinib for 18 weeks & $84 \%$ of tumor reduction & $\begin{array}{l}\text { Total thyroidectomy, modified } \\
\text { neck dissection, resection of the } \\
\text { muscular layer of the esophagus, } \\
\text { and a tracheal sleeve resection } \\
\text { and reconstruction }\end{array}$ & Alive without distant metastases \\
\hline Danilovic et al. & Brazil/2018 & $\begin{array}{l}\text { Case } \\
\text { report/PTC }\end{array}$ & 1 & 20 & Sorafenib for 13 months & $\begin{array}{l}\text { Tumor reduction that } \\
\text { allowed surgical therapy }\end{array}$ & $\begin{array}{l}\text { Near total thyroidectomy and } \\
\text { bilateral neck dissection }\end{array}$ & Structural incomplete response \\
\hline Nava et al. & Brazil/2019 & $\begin{array}{l}\text { Case } \\
\text { report/PTC }\end{array}$ & 1 & 32 & Sorafenib for 6 months & $70 \%$ tumor reduction & $\begin{array}{l}\text { Total thyroidectomy, left jugular } \\
\text { chain dissection, shaving of } \\
\text { trachea, and esophagus }\end{array}$ & $\begin{array}{l}\text { Biochemical incomplete } \\
\text { response }\end{array}$ \\
\hline
\end{tabular}

ChT, chemotherapy; RhT, radiotherapy; PTC, papillary thyroid carcinoma; MTC, medullary thyroid carcinoma; RAl, radioiodine therapy; NA, not available; *poorly differentiated PTC; Classical PTC; Follicular variant of PTC; and Hurthle cell variant of PTC. 
showed the use of MKI as neoadjuvant therapy for locally advanced DTC in 4 case reports; Tumor reduction was observed in all cases, allowing posterior surgery, three of them with complete resection. These data point out MKIs as an effective and feasible alternative for unresectable locally advanced thyroid tumors, potentially changing the course of the disease in those patients with advanced local disease.

An original aspect of this study was the opportunity to evaluate the histopathological changes secondary to MKI therapy in a PTC specimen. Gross pathological examination showed a significant reduction in the tumor size while microscopic examination revealed a fibrotic and hemorrhagic residual tumor. Changes in VEGF and VEGFR immunohistochemical staining, together with decreases of the CD31-positive intratumoral vascular network, corroborate the powerful antiangiogenic and antiproliferative effect of sorafenib on thyroid tumor cells. Of interest, Yuen et al. described similar findings in a renal cell carcinoma xenograft model where sorafenib-treated mice showed reduced mean percentage of CD-31-positive endothelial cells (27).

In summary, the use of MKI neoadjuvant therapy is particularly beneficial for locally advanced thyroid carcinomas. Our observations shed light on new treatment strategies, which can potentially minimize morbidity, improving disease status and long-term prognosis in a subgroup of patients with locally aggressive thyroid carcinoma.

\section{REFERENCES}

1. Bray F, Ferlay J, Soerjomataram I, Siegel RL, Torre LA, Jemal A. Global cancer statistics: GLOBOCAN estimates of incidence and mortality worldwide for 36 cancers in 185 countries. CA Cancer J Clin. (2018) 68:394-424. doi: $10.3322 /$ caac. 21492

2. Shah JP. Thyroid carcinoma: epidemiology, histology, and diagnosis. Clin Adv Hematol Oncol. (2015) 13:3-6.

3. Lim H, Devesa SS, Sosa JA, Check D, Kitahara CM. Trends in thyroid cancer incidence and mortality in the United States, 1974-2013. JAMA. (2017) 317:1338-48. doi: 10.1001/jama.2017.2719

4. Haugen BR, Alexander EK, Bible KC, Doherty GM, Mandel SJ, Nikiforov YE, et al. 2015 American Thyroid Association management guidelines for adult patients with thyroid nodules and differentiated thyroid cancer. Thyroid. (2016) 26:1-133. doi: 10.1089/thy.2015.0020

5. Pacini F, Castagna MG, Brilli L, Pentheroudakis G, ESMO Guidelines Working Group. Thyroid cancer: ESMO Clinical Practice Guidelines for diagnosis, treatment and follow-up. Ann Oncol. (2012) 23:vii110-9. doi: 10.1093/annonc/mds230

6. Rosário PW, Ward LS, Carvalho GA, Graf H, Maciel RM, Maciel LM, et al. Thyroid nodules and differentiated thyroid cancer: update on the Brazilian consensus. Arq Bras Endocrinol Metabol. (2013) 57:240-64. doi: 10.1590/S0004-27302013000400002

7. Antonelli A, Bocci G, La Motta C, Ferrari SM, Fallahi P, Fioravanti A, et al. Novel pyrazolopyrimidine derivatives as tyrosine kinase inhibitors with antitumoral activity in vitro and in vivo in papillary dedifferentiated thyroid cancer. JClin Endocrinol Metab. (2011) 96:E288-96. doi: 10.1210/jc.2010-1905

8. Fallahi P, Ferrari SM, Santini F, Corrado A, Materazzi G, Ulisse S, et al. Sorafenib and thyroid cancer. BioDrugs. (2013) 27:615-28. doi: 10.1007/s40259-013-0049-y

\section{DATA AVAILABILITY STATEMENT}

The datasets generated for this study are available on request to the corresponding author.

\section{ETHICS STATEMENT}

Ethical review and approval was not required for the study on human participants in accordance with the local legislation and institutional requirements. The patients/participants provided their written informed consent to participate in this study.

\section{AUTHOR CONTRIBUTIONS}

CN, RS, JD, and ALM contributed to the study conception, design, data analysis, interpretation, and manuscript preparation. CN, AC, CF, SW, AZ, FP, AM, MG, JG, and ALM were responsible for data collection, data analysis, and manuscript preparation. All authors read and approved the final manuscript version.

\section{FUNDING}

This work has been made possible by grants from Conselho Nacional de Desenvolvimento Científico e Tecnológico (CNPq), Coordenação de Aperfeiçoamento de Pessoal de Nível Superior (CAPES), Fundo de Incentivo a Pesquisa (FIPE), and Programa de Apoio a Núcleos de Excelência (PRONEX)/Fundação de Amparo à Pesquisa do Estado do Rio Grande do Sul (FAPERGS).

9. Brose MS, Nutting CM, Jarzab B, Elisei R, Siena S, Bastholt L, et al. Sorafenib in locally advanced or metastatic, radioactive iodine-refractory, differentiated thyroid cancer: a randomized, double-blind, phase 3 trial. Lancet. (2014) 384:319-28. doi: 10.1016/S0140-6736(14)60421-9

10. Schlumberger M, Tahara M, Wirth LJ, Robinson B, Brose MS, Elisei R, et al. Lenvatinib versus placebo in radioiodine-refractory thyroid cancer. $N$ Engl J Med. (2015) 372:621-30. doi: 10.1056/NEJMoa1406470

11. DeVita VT Jr, Chu E. A history of cancer chemotherapy. Cancer Res. (2008) 68:8643-53. doi: 10.1158/0008-5472.CAN-07-6611

12. Ziogas IA, Tsoulfas G. Evolving role of Sorafenib in the management of hepatocellular carcinoma. World J Clin Oncol. (2017) 8:203-13. doi: 10.5306/wjco.v8.i3.203

13. Escudier B, Porta C, Schmidinger M, Rioux-Leclercq N, Bex A, Khoo $\mathrm{V}$, et al. Renal cell carcinoma: ESMO Clinical Practice Guidelines for diagnosis, treatment and follow-up. Ann Oncol. (2014) 25:iii49-56. doi: 10.1093/annonc/mdu259

14. Guo G, Cai W, Li H, Gao J, Ma X, Dong J, et al. Presurgical neoadjuvant targeted molecular therapy for kidney cancer with concomitant vena cava tumor embolus: a clinical study. Oncol Lett. (2017) 14:369-75. doi: $10.3892 /$ ol.2017.6131

15. Eisenhauer EA, Therasse P, Bogaerts J, Schwartz LH, Sargent D, Ford $\mathrm{R}$, et al. New response evaluation criteria in solid tumors: revised RECIST guideline (version 1.1). Eur J Cancer. (2009) 45:228-47. doi: 10.1016/S1359-6349(09)70018-7

16. Romitti M, Wajner SM, Ceolin L, Ferreira CV, Ribeiro RV, Rohenkohl HC, et al. MAPK and SHH pathways modulate type 3 deiodinase expression in papillary thyroid carcinoma. Endocr Relat Cancer. (2016) 23:135-46. doi: 10.1530/ERC-15-0162

17. Moher D, Liberati A, Tetzlaff J, Altman DG, PRISMA Group. Preferred reporting items for systematic reviews and meta-analyses: 
the PRISMA statement. J Clin Epidemiol. (2009) 62:1006-12. doi: 10.1016/j.jclinepi.2009.06.005

18. Besic N, Auersperg M, Gazic B, Dremelj M, Zagar I. Neoadjuvant chemotherapy in 29 patients with locally advanced follicular or hurthle cell thyroid carcinoma: a phase 2 study. Thyroid. (2012) 22:131-7. doi: 10.1089/thy.2011.0243

19. Besic N, Auersperg M, Dremelj M, Vidergar-Kralj B, Gazic B. Neoadjuvant chemotherapy in 16 patients with locally advanced papillary thyroid carcinoma. Thyroid. (2013) 23:178-84. doi: 10.1089/thy.2012.0194

20. Shingu K, Kobayashi S, Yokoyama S, Shimizu T, Kasuga Y, Fujimori M, et al. Effectiveness of preoperative radioactive iodine (131I) therapy for locally advanced papillary thyroid cancer: a case report. Thyroid. (1998) 8:1113-6. doi: 10.1089/thy.1998.8.1113

21. Cleary JM, Sadow PM, Randolph GW, Palmer EL, Lynch TP, Nikiforov YE, et al. Neoadjuvant treatment of unresectable medullary thyroid cancer with sunitinib. J Clin Oncol. (2010) 28:e390-2. doi: 10.1200/JCO.2009.27.4225

22. Tsuboi M, Takizawa H, Aoyama M, Tangoku A. Surgical treatment of locally advanced papillary thyroid carcinoma after response to lenvatinib: a case report. Int J Surg Case Rep. (2017) 41:89-92. doi: 10.1016/j.ijscr.2017.10.010

23. Danilovic DLS, Castro G, Roitberg FSR, Vanderlei FAB, Bonani FA, Freitas RMC, et al. Potential role of sorafenib as neoadjuvant therapy in unresectable papillary thyroid cancer. Arch Endocrinol Metab. (2018) 62:3705. doi: 10.20945/2359-3997000000046

24. Shindo ML, Caruana SM, Kandil E, McCaffrey JC, Orloff LA, Porterfield JR, et al. Management of invasive well-differentiated thyroid cancer: an American head and neck society consensus statement. Head Neck. (2014) 36:1379-90. doi: 10.1002/hed.23619

25. Mellière DJ, Ben Yahia NE, Becquemin JP, Lange F, Boulahdour H. Thyroid carcinoma with tracheal or esophageal involvement: limited or maximal surgery? Surgery. (1993) 113:166-72.

26. Nishida T, Nakao K, Hamaji M. Differentiated thyroid carcinoma with airway invasion: indication for tracheal resection based on the extent of cancer invasion. $J$ Thorac Cardiovasc Surg. (1997) 114:84-92. doi: 10.1016/S0022-5223(97) 70120-X

27. Yuen JS, Sim MY, Siml HG, Chong TW, Lau WK, Cheng CW, et al. Inhibition of angiogenic and non-angiogenic targets by sorafenib in renal cell carcinoma (RCC) in a RCC xenograft model. Br J Cancer. (2011) 104:941-7. doi: 10.1038/bjc.2011.55

Conflict of Interest: ALM has served as an advisor/speaker for Sanofi-Genzyme within the past 2 years. ALM and CF have served as principal investigator and coordinator, respectively, in multicenter studies for Astra-Zeneca and SanofiGenzyme within the past 2 years.

The remaining authors declare that the research was conducted in the absence of any commercial or financial relationships that could be construed as a potential conflict of interest.

Copyright (c) 2019 Nava, Scheffel, Cristo, Ferreira, Weber, Zanella, Paixão, Migliavaca, Guimarães, Graudenz, Dora and Maia. This is an open-access article distributed under the terms of the Creative Commons Attribution License (CC BY). The use, distribution or reproduction in other forums is permitted, provided the original author(s) and the copyright owner(s) are credited and that the original publication in this journal is cited, in accordance with accepted academic practice. No use, distribution or reproduction is permitted which does not comply with these terms. 